\title{
PSYCHOPATHOLOGY AND 5-HYDROXYINDOLEACETIC ACID EXCRETION
}

\author{
ARTHUR YUWILER* \\ Schizophrenia and Psychopharmacology Joint Research Project, \\ University of Michigan and Ypsilanti State Hospital
}

(Received 15 February 1965)

(Revised 6 April 1965)

\section{INTRODUCTION}

CONSIDERABLE indirect evidence, associating serotonin with central nervous system function and the actions of important psychotropic drugs, led to suggestions ${ }^{1,2}$ of a relationship between serotonin metabolism and schizophrenia. Despite considerable effort, experimental support for this suggestion has been inconclusive. Among studies in this area are those on quantitative excretion, and variability of excretion, of serotonin's major metabolite, 5hydroxyindoleacetic acid, by various diagnostic populations, and on the relationship between such excretion and clinical symptomatology. Thus, schizophrenics have been reported variously to excrete supernormal, ${ }^{3-5}$ subnormal, ${ }^{6}$ and normal ${ }^{7-13}$ amounts of this metabolite, and to show excessive variability in excretion. More recently a direct relationship between urinary levels of 5-hydroxyindoleacetic acid and other tryptophan metabolites and clinical symptomatology has been reported. ${ }^{15-18}$

As part of a larger multidisciplinary study on the attributes of schizophrenia, $\dagger$ it was possible to examine some of these reports on a large population maintained under controlled conditions. ${ }^{19,20}$ The present paper deals with a comparison of the quantitative excretion of 5-hydroxyindoleacetic acid by various diagnostic populations, and an analysis of the correlations between such excretion and pertinent biological and behavioral variables.

\footnotetext{
* Present address: Neurobiochemistry Laboratory, Veterans Administration Center, Wilshire and Sawtelle Boulevards, Los Angeles, California 90073.

† This investigation was carried out as part of the Schizophrenia and Psychopharmacology Joint Research Project, supported by USPHS MY-1972, MY-4567 and MH-07293-01. The author is indebted to Mr. T. Best for technical assistance, Mr. N. Mattsson for statistical holp, and Drs. R. W. Gerard, S. Gershon and E. Geller for their helpful comments.
} 


\section{MATERIALS AND METHODS}

Subjects. Schizophrenic and nonschizophrenic subjects 18-50 years of age were drawn from the male population of Ypsilanti State Hospital. Admission to the research ward was contingent upon unanimous concordance on primary diagnosis (obtained independently by three psychiatrists) and the absence of concurrent physical illnesses. All psychiatrists had access to the medical records.

Diagnostic subdivisions into paranoid schizophrenic, non paranoid schizophrenic, nonschizophrenic with chronic brain syndrome, and nonschizophrenic without chronic brain syndrome were established by the majority judgment of the three psychiatrists on the predominant psychiatric and medical state of the subjects. While unanimity was not required, it was achieved in the majority of cases. 123 subjects (63 schizophrenics and 60 nonschizophrenics) were admitted to the research ward in diagnostically mixed groups of five. Medication was terminated two months before testing, and subjects were maintained on an unvarying diet with daily vitamin supplementation throughout their stay on the research ward. A three-week period of dietary adjustment was allowed. Baseline biochemical determinations were made during the fourth week when diet was rigidly controlled and ward obscrvation carried out. Specimens were discarded from subjects failing to consume their diet completely. The mean age of the schizophrenics in this study was $35 \cdot 8 \pm 8 \cdot 25^{*}$ years, and they had been hospitalized for $54.4 \pm 77 \cdot 4$ months. Psychiatric and ward ratings were carried out using Lorr MSRPP ${ }^{21}$ and the Gorham Ward Rating Scale. ${ }^{22}$

Specimens. Urines were collected over 24-hour periods and were refrigerated at $5^{\circ} \mathrm{C}$ between collections. Analytical determinations werc carricd out daily. Estimations of 5-hydroxyindoleacetic acid were not carried out on samples having a $\mathrm{pH}$ greater than 6.9. Methods. Urinary 5-hydroxyindoleacetic acid was estimated by the procedure of UDENFRIEND et al. ${ }^{23}$ creatinine by a Jaffe reaction ${ }^{24}$ and sodium by flame photometry. In most instances individual figures for 5-hydroxyindoleacetic acid and sodium are the average of two samples taken two days apart, while figures for total volume and urinary creatininc are the means for five determinations. Reported values, therefore, are the means of such individual averages. Cross- and intra-correlations were computed from daily individual 24-hour values, rather than pooled mean values, and the variables in question.

\section{RESULTS AND DISCUSSION}

Comparisons of the 5-hydroxyindoleacetic acid excretion by various diagnostic populations (Table 1) substantiate those investigations ${ }^{7-14}$ concluding that schizophrenics and nonschizophrenics do not differ in 5-hydroxyindoleacetic acid excretions. Non paranoid schizophrenics did differ significantly $(P<0.05)$ from both paranoid schizophrenics and nonschizophrenics with chronic brain syndrome in the urinary concentration of 5-hydroxyindoleacetic acid but not in total daily excretion. However, of the 30 cross comparisons

\footnotetext{
* Mean \pm standard deviation.
} 


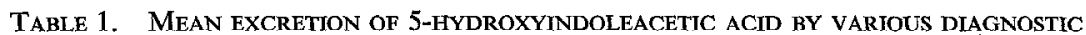
POPULATIONS

\begin{tabular}{lccccc}
\hline & $N$ & $\begin{array}{r}\text { Mean } \\
\mu \mathrm{g} / \mathrm{ml}\end{array}$ & $\begin{array}{c}\text { S.D. } \\
\mu \mathrm{g} / \mathrm{ml}\end{array}$ & $\begin{array}{r}\text { Mean } \\
\mathrm{mg} / 24 \mathrm{~h}\end{array}$ & $\begin{array}{c}\text { S.D. } \\
\mathrm{mg} / 24 \mathrm{~h}\end{array}$ \\
\hline Schizophrenics & 63 & $4 \cdot 47$ & $2 \cdot 58$ & $4 \cdot 46$ & $2 \cdot 35$ \\
Paranoid & 22 & 3.86 & $1 \cdot 70^{*}$ & $5 \cdot 28$ & $2 \cdot 62$ \\
Nonparanoid & 41 & $4 \cdot 79$ & $2 \cdot 92^{*}$ & 4.02 & $2 \cdot 08$ \\
Nonschizophrenics & 60 & $4 \cdot 36$ & $2 \cdot 34$ & 5.06 & $2 \cdot 76$ \\
CBS $\dagger$ & 22 & 4.65 & $2 \cdot 59^{*}$ & 5.54 & 3.49 \\
Non CBS & 38 & 4.23 & $2 \cdot 26$ & 4.69 & $2 \cdot 27$ \\
\hline
\end{tabular}

* Nonparanoid schizophrenics differ from paranoid schizophrenics $P<0.05$, and from nonschizophrenics with chronic brain syndrome $P<0 \cdot 05$.

$\uparrow$ Nonschizophrenics with chronic brain syndrome.

TABLE 2. RELATIONSHIP BETWEEN SELECTED PSYCHIATRIC FACTORS AND 24 h 5 -HYDKOXYINDOLEACETIC ACID EXCRETION BY SCHIZOPHRENICS

\begin{tabular}{|c|c|c|c|c|c|}
\hline Psychiatric item definition & $N$ & $r^{*}$ & $P \dagger$ & $P+$ & S-NS\& \\
\hline Lorr A-Depression vs excitement & 60 & +0.176 & NS & $<0.001$ & + \\
\hline Lorr $\mathbf{B}-$ Compliance vs resistiveness & 61 & -0.027 & NS & $<0.05$ & + \\
\hline Lorr C-Paranoid projection & 59 & -0.095 & NS & $<0.001$ & + \\
\hline Lorr D-Activity (under vs over) & 60 & +0.067 & NS & $<0.01$ & - \\
\hline Lorr E-Melancholy agitation & 60 & $+0 \cdot 110$ & NS & $<0.01$ & - \\
\hline Lorr F-Perceptual distortion & 60 & -0.085 & NS & $<0.001$ & + \\
\hline $\begin{array}{l}\text { Lorr G-Motor disturbance } \\
\text { Lorr } \mathrm{H}-\text { Submissive vs belligerent }\end{array}$ & $\begin{array}{l}61 \\
61\end{array}$ & $\begin{array}{l}-0.227 \\
+0.030\end{array}$ & $\begin{array}{l}\text { NS }(<0 \cdot 1) \\
\text { NS }\end{array}$ & $\begin{array}{l}<0.001 \\
<0.001\end{array}$ & + \\
\hline Lorr I-Withdrawal (more vs less) & 61 & +0.413 & $<0.001$ & $<0.001$ & - \\
\hline $\begin{array}{l}\text { Lorr J- Self depreciation vs gran- } \\
\text { doise expansion }\end{array}$ & 61 & $-0 \cdot 107$ & NS & NS & + \\
\hline Lorr K-Conceptual disorganization & 60 & $-0 \cdot 222$ & $\mathrm{NS}(<0 \cdot 1)$ & $<0.001$ & + \\
\hline Gorham 1 -Activity level & 61 & $+0 \cdot 180$ & NS & $<0.01$ & - \\
\hline Gorham 2-Anxiety level & 61 & -0.104 & NS & $<0.001$ & + \\
\hline Gorham 3-Mental disorganization & 61 & -0.262 & $<0.05$ & $<0.001$ & + \\
\hline $\begin{array}{l}\text { Gorham 4-Mood (depressed vs } \\
\text { euphoric) } \\
\text { Gorham 5-Interpersonal relations }\end{array}$ & 61 & $+0 \cdot 114$ & NS & $<0.01$ & - \\
\hline $\begin{array}{l}\text { (less vs more withdrawn) } \\
\text { (lituams }\end{array}$ & 61 & -0.373 & $<0.01$ & $<0.001$ & + \\
\hline Gorham 6-Anger & 61 & +0.076 & NS & NS & + \\
\hline
\end{tabular}

* Pearson correlation coefficient.

$\uparrow$ Probability of the correlation; NS signifies not significant.

\$Distinguish between schizophrenics and nonschizophrenics at the indicated probability level.

$\S+$ Mean for schizophrenics greater than mean for nonschizophrenics.

- Mean for schizophrenics less than mean for nonschizophrenics. 
between schizophrenics, nonschizophrenics, and their various sub-populations in this analysis, one and one-half differences of the 0.05 level would be expected by chance alone, and it is unlikely that the two statistical differences observed had clinical significance.

It is also of interest that the variance was nearly identical for schizophrenics and nonschizophrenics; and ranges of individual values for 24-hour excretion was also comparable between these groups. The extreme valucs for schizophrenics ranged from $1.09 \mathrm{mg} / 24 \mathrm{~h}$ (a non paranoid schizophrenic) to $12.79 \mathrm{mg} / 24 \mathrm{~h}$ (a paranoid schizophrenic) while the extremes among nonschizophrenics were $1.11 \mathrm{mg} / 24 \mathrm{~h}$ to $11.69 \mathrm{mg} / 24 \mathrm{~h}$ (two nonschizophrenics without chronic brain syndrome). Thus, it would appear that schizophrenics do not show greater variability than nonschizophrenics on this measure when both are maintained under similar environmental conditions.

It has been suggested ${ }^{17}$ that 'exacerbations of schizophrenic activity in terms of aggravations of hallucinatory and delusional experiences as well as agressiveness and hostility'. are accompanied by increased urinary excretion of tryptamine, indole-3-acetic acid, and 5-hydroxyindoleacetic acid. Correlations between 5-hydroxyindoleacetic acid excretion and various pertinent behavioral and biological variables were analyzed, therefore, to assess the validity of the postulated relationship for this compound. The correlations between metabolite excretion and LORR $^{21}$ and GoRHAM ${ }^{22}$ rating factors, presented in Table 2, not only fail to support this suggested relationship, but even suggest the opposite trend, of decreasing psychopathology with increasing 5-hydroxyindoleacetic acid excretion. Excretion of 5-hydroxyindoleacetic acid correlated significantly with withdrawal on both the Gorham 5 and Lorr I in the direction of less withdrawal with higher excretion, and with the Mental Disorganization Factor, Gorham 3, in the direction of less mental disorganization with higher excretion. Correlations with other rating factors failed to reach statistical significance, but, with the exception of the Lorr A, all were in the direction of decreased schizophrenic psychopathology with increased 5-hydroxyindoleacetic acid excretion. The Lorr I and the Gorham 5 in this study correlated remarkably well for these types of measures ( $r=0.764, P=0.001, N=99$ ) so that both factors seem to be estimating similar phenomena. Although single rating factors may not fully reflect global pathology, 15 of the 17 Lorr and Gorham scale items distinguished schizophrenics from nonschizophrenics in this study and 10 did so at $P<0 \cdot 001$.

Because of the difficulty in specifying clinical state and environmental conditions precisely it is conceivable that the negative relationship between 5-hydroxyindoleacetic acid and psychopathology observed in this cross-sectional study and the positive relationship reported in longitudinal studies may reflect extraneous influences on 5-hydroxyindoleacetic acid excretion. For example, the nine schizophrenic subjects studies by BERLET et al. ${ }^{17}$ ranged in age from 39-59 years (mean 53) and were hospitalized for from 6-28 years (mean 19). The schizophrenics in our study were younger $(35.8 \pm 8 \cdot 2$ years of age) and had been hospitalized for a lesser period $(4.53 \pm 6.45$ years). However, in our study, hospitalization (but not age) correlated negatively with 5-hydroxyindoleacetic acid excretion ( $r=-0 \cdot 381$; $P<0 \cdot 01$ ), so that neither experimental difference alone appears to account for the differences in the findings. As expected, hospitalization and, to a lesser extent, age correlated positively with increasing psychopathology (Table 3). 
TABLE 3. RELATIONSHIP AMONG SCHIZOPHRENICS BFTWFFN PSYCHIATRIC RATING FACTORS, AGE AND HOSPITALIZATION, URINE VOLUME AND URINARY CREATININE

\begin{tabular}{|c|c|c|c|c|c|c|c|c|}
\hline \multirow[t]{2}{*}{ Rating faclor } & \multicolumn{2}{|c|}{ Age } & \multicolumn{2}{|c|}{ Hospitalization } & \multicolumn{2}{|c|}{ Urine volume } & \multicolumn{2}{|c|}{ Creatinine } \\
\hline & $r^{*}$ & $P \dagger<$ & $r$ & $P<$ & $r$ & $P<$ & $r$ & $P<$ \\
\hline Lorr A & & NS & & NS & +0.238 & 0.05 & +0.268 & 0.01 \\
\hline B & & NS & +0.237 & 0.05 & -0.202 & 0.05 & -0.271 & 0.01 \\
\hline $\mathrm{C}$ & & NS & & NS & & NS & & NS \\
\hline $\mathrm{D}$ & & NS & -0.222 & 0.05 & $+0 \cdot 248$ & 0.05 & & NS \\
\hline $\mathrm{E}$ & -0.231 & 0.05 & -0.251 & 0.05 & +0.201 & 0.05 & & NS \\
\hline $\mathrm{F}$ & & NS & & NS & & NS & -0.257 & 0.05 \\
\hline G & & NS & & NS & & NS & -0.268 & 0.01 \\
\hline H & -0.272 & 0.01 & $-0 \cdot 194$ & 0.05 & & NS & & NS \\
\hline I & -0.236 & 0.05 & -0.514 & 0.001 & +0.406 & 0.001 & +0.485 & 0.001 \\
\hline $\mathbf{J}$ & & NS & & NS & & NS & & NS \\
\hline $\mathbf{K}$ & & NS & +0.268 & 0.01 & & NS & -0.382 & 0.001 \\
\hline Gorham 1 & & NS & $-0 \cdot 199$ & 0.05 & +0.250 & 0.05 & +0.220 & 0.05 \\
\hline 2 & & NS & & NS & & NS & -0.212 & 0.05 \\
\hline 3 & +0.189 & 0.05 & +0.521 & 0.001 & -0.265 & 0.01 & -0.445 & 0.001 \\
\hline 4 & & NS & & NS & +0.240 & 0.05 & & NS \\
\hline 5 & +0.264 & 0.01 & +0.399 & 0.001 & -0.364 & 0.001 & -0.444 & 0.001 \\
\hline 6 & $-0 \cdot 191$ & 0.05 & -0.231 & 0.05 & & NS & & NS \\
\hline
\end{tabular}

* Pearson correlation coefficient.

$\uparrow$ Probability of the correlation; NS signifies not significant.

The most reasonable remaining explanation of these findings is that 5-hydroxyindoleacetic acid reflects physical changes resulting from or accompanying psychopathology. Thus, and in agreement with the findings of BERLET $e\left(a l .{ }^{26}, 24 \mathrm{~h}\right.$ creatinine excretion correlated with 5-hydroxyindoleacetic acid excretion $(r=+0.588 ; N=61 ; P<0.001)$, as did $24 \mathrm{~h}$ urine volume $(r=+0.399 ; P<0.001), 24 \mathrm{~h}$ urinary sodium $(r=+0.506 ; P<0.001)$, and $24 \mathrm{~h}$ urinary potassium excretion $(r=+0.404 ; P<0.001)$. Further, these latter variables also generally correlated with psychiatric items in the direction of decreasing values with increasing psychopathology (Table 3), the opposite direction from that reported by BeRLEI et al. ${ }^{26}$ As anticipated, creatinine excretion, in this study, correlated positively for both schizophrenics and nonschizophrenics with such anthropometric measures as body weight, calf girth and lean body weight. Hospitalization, however, correlated negatively with the creatinine excretion of schizophrenics and positively with excretion by nonschizophrenics. A possible interpretation is that this reflects a gradual physical deterioration among schizophrenics during chronic hospitalization, in contrast to a physical restoration among nonschizophrenics, particularly sociopaths, during their shorter hospitalization. Chronic schizophrenic psychopathology, then, would be accompanied by a continued loss of muscle mass, reflected in decreased creatinine excretion, and decreased 5-hydroxyindoleacetic acid excretion. Transitory exacerbations of psychopathology superimposed on this basic pattern could temporarily hasten this degenerative process, increasing creatinine excretion during rapid loss of muscle mass, as suggested by BERLET et al., and concommitantly heighten excretion of 5-hydroxyindoleacetic acid. This interpretation, while reconciling 
these apparently discrepant findings, also suggests that 5-hydroxyindoleacetic acid excretion is more closely related to physical state than to psychopathology: however, a direct relationship between psychopathology and indole excretion is not excluded particularly since 5-hydroxyindoleacetic acid is considered a less sensitive indication of behavioral change than is tryptamine or indole-3-acetic acid.

\section{SUMMARY}

Schizophrenics and nonschizophrenics do not differ in urinary excretion of 5-hydroxyindoleacetic acid on either a concentration or $24 \mathrm{~h}$ basis, nor do they differ in variability of excretion. Although a pattern was observed of decreasing psychopathology with increasing 5-hydroxyindoleacetic acid excretion, this pattern may be related to alterations in physical state accompanying psychopathology rather than to psychopathology per se.

\section{REFERENCES}

1. WoOlLeY, D. W. and SHAw, E. A biochemical and pharmacological suggestion about certain mental disorders. Science 119, 587, 1954.

2. Gaddum, J. H. Drugs antagonistic to 5-hydroxytryptamine. Ciba Foundation Symposium on Hypertension, p. 75, Little, Brown and Co., Boston, 1954.

3. BanerJee, S. and Agarwal, P. S. Tryptophan-nicotinic acid metabolism in schizophrenia. Proc. Soc. exp. Biol. Med. 97, 657, 1958.

4. MASUdA, M., SLONECKER, J. S. and DORPaT, T. L. Urinary aromatic metabolites in schizophrenia. J. nerv. ment. Dis. 130, 125, 1960.

5. Villar Palast, V. and Solduga, J. Metabolites de la serotonine et diagnostique differentiel. 5th International Congress of Biochemistry, Vol. 9, p. 418, Abstract \#16.79, Pergamon Press, Oxford, 1961.

6. LeYton, G. B. Indolic compounds in the urine of schizophrenics. Br. med. J. 2, 1136, 1958.

7. Buscaino, G. A. and STEFANACHI, L. Metabolism of indoleic substances, especially 5-hydroxyindoleacetic acid, in schizophrenia. Confinia neurol. 18, 188, 1958.

8. Buscaino, G. A. and Stefanachi, L. Urinary excretion of 5-hydroxyindoleacetic acid in psychotic and normal subjects excretion after parenteral administration of serotonin. A.M.A. Archs Neurol. Psychiatry 80, 78, 1958.

9. Feldstein, A., Hoagland, H. and Freeman, H. Blood and urinary serotonin and 5-hydroxyindoleacetic acid levels in schizophrenic patients and normal subjects. J. nerv. ment. Dis. 129, 62, 1959.

10. Feldstein, A., Hoagland, H. and Freemen, H. On the relationship of serotonin to schizophrenia. Science 128, 358, 1958.

11. Haverback, B. J., SJoerdsma, A. and Terry, L. L. Urinary excretion of the serotonin metabolite, 5-hydroxyindoleacetic acid, in various clinical conditions. New Engl. J. Med. 255, 270, 1956.

12. REIGELHAUPT, L. M. Investigation of urinary excretion patterns in psychiatric subjects. $J$. nerv. ment. Dis. 127, 22, 1958.

13. Robins, E., Lowe, I. P. and HAVner, N. M. The urinary excretion of 5-hydroxy-3-indoleacetic acid (HIAA in patients with schizophrenia and in control subjects. Clin. Res. Proc. 4, 149, 1956.

14. Sano, I., Kakimoto, Y., OKamoto, T., Nakajma, H. and Kudo, Y. 5-Hydroxyindoleacetic acid excretion in urine of schizophrenics with reference to effects of chlorpromazine and reserpine on serotonin metabolism. Schweiz med. Wschr. 87, 214, 1957.

15. BRuNe, G. G. and Hrmwich, H. E. Biphasic action of reserpine and isocarboxazid and serotonin metabolism. Science 133, 190, 1961. 
16. Brtine, G. G. and Pschrmot, G. R. Correlations between behavior and urinary excretion of indole amines and catecholamines in schizophrenic patients as affected by drugs. Fedn Proc. Fedn Am. Socs. exp. Biol. 20, 889, 1961.

17. Berlet, H. H., Bull, C., Himwich, H. E., Kohl, H., Matsomoto, K., Pschemt, G. R., Spaide, J., ToORLENTES, T. T. and VALVERDE, J. M. Endogenous metabolic factor in schizophrenic behavior. Science 144, 311, 1961.

18. Brune, G. G. and Himwich, H. E. Biogenic amines and behavior in schizophrenic patients. Recent Advances in Biological Psychiatry, J. Worlis (Ediior), p. 144, Vol. 5, Plenum Press, New York, 1963.

19. Gerard, R. W., et al. The nosology of schizophrenia. Am. J. Psychiat. 120, 16, 1963.

20. Gerard, R. W. Nosology of schizophrenia: a co-operative study, Behavl. Sci. 9, 311, 1964.

21. LoRr, M. Multidimensional scale for rating psychiatric patients. Veterans Administration Technical Bulletin TB 10-5-7, Nov. 1953.

22. Gorham, D. R. AMI Psychiatric behavior rating scales. Veterans Administration Form 10-166 (4049). May, 1958.

23. Udenfriend, S., Titus, E. and Weissbach, H. The identification of 5-hydroxy-3-indoleacetic acid in normal urine and a method for its assay. J. biol. Chem. 216, 499, 1955.

24. Clark, L. C., JR. and Thompson, H. L. Determination of creatine and creatinine in urine. Analyt. Chem. 21, 1218, 1949.

25. Brune, G. G. and Himwich, H. E. Indole metabolites in schizophrenic patients. Urinary excretion. Archs. gen. Psychiat. 6, 324, 1962.

26. Berlet, H. H., Pscheidt, G. R., SPAIde, J. K. and Himwich, H. E. Variations of urinary creatinine and its correlation to tryptamine excretion in schizophrenic patients. Nature, Lond. 203, 1198, 1964. 